\title{
Rancang Bangun Sistem Pengukuran Medan Magnet Menggunakan LabVIEW, CONTROLLER NI cRIO-9022, dan DTM-151 Digital Teslameter
}

\author{
Musaffiriyan Rasyid Ghoni*1 ${ }^{1}$, Andi Dharmawan ${ }^{2}$, Slamet Santosa ${ }^{3}$ \\ ${ }^{1}$ Program Studi Elektronika dan Instrumentasi \\ ${ }^{2}$ Jurusan Ilmu Komputer dan Elektronika, FMIPA UGM, Yogyakarta \\ ${ }^{3}$ Pusat Teknologi Akselerator dan Proses Bahan (PTAPB) BATAN, Yogyakarta \\ e-mail: *11 musaffiriyan.rg@gmail.com,,${ }^{2}$ dharmawan.andi@gmail.com, ${ }^{3}$ santosa@ batan.go.id
}

\section{Abstrak}

Pusat Teknologi Akselerator dan Proses Bahan (PTAPB) BATAN Yogyakarta sedang mengembangkan sistem pengukuran medan magnet untuk alat siklotron. Pengukuran medan magnet pada siklotron diperlukan untuk mengetahui besar dan arah dari medan magnet. Sistem ini menggunakan LabVIEW untuk membuat aplikasi antarmuka (HMI) dan pemrograman sistem. Implementasi fungsi kendali menggunakan controller NI cRIO-9022 yang dirangkai dengan modul NI 9512, yang akan mengatur kerja komponen penggerak, yaitu stepper motor. Implementasi fungsi akuisisi data menggunakan DTM-151 Digital Teslameter untuk mengukur kuat medan magnet. Pengukuran menggunakan bidang koordinat kartesian $(x, y)$.

Sebuah magnet permanen digunakan sebagai objek uji pengukuran. Ukuran magnet uji lebih kecil dari dimensi pengukuran sistem sehingga dimensi pengukuran terhadap bidang magnet dibuat berukuran $(100 \times 100) \mathrm{mm}$. Koordinat posisi awal teslameter 1 dan teslameter 2, secara berurutan, adalah (430,720) dan (430,240). Pengujian dilakukan sebanyak 2 kali $(2$ posisi magnet yang berbeda). Masing-masing pengujian dilakukan 3 kali pengukuran sehingga didapatkan 6 file data. Dari jumlah file data tersebut didapatkan jumlah data dengan rata-rata 1.117 data setiap file-nya. Kecepatan putar motor yang digunakan saat pengujian adalah 25 $\mathrm{mm} / \mathrm{s}$. Laju pembacaan data sebesar 10 data/s, interval dari perubahan posisi ketika motor berputar bernilai $2,5 \mathrm{~mm}$.

Kata kunci-sistem pengukuran medan magnet, LabVIEW, controller,teslameter, stepper motor, metode kendali on-off, komunikasi serial.

\section{Abstract}

Pusat Teknologi Akselerator dan Proses Bahan (PTAPB) BATAN Yogyakarta currently developing a magnetic field measurement system for cyclotron machine. Magnetic field measurement on cyclotron is required to determine the magnitude and direction of the magnetic field.

The system used LabVIEW to create an interface application (HMI) and system programming. The control function implemented by using controller NI cRIO-9022 combined with NI 9512 module, which would controlling the motion component, that isthe stepper motor. The acquisition data function implemented by using DTM-151 Digital Teslameter to measure the magnetic field. The measurement works within the cartesian coordinate plane $(x, y)$.

A permanent magnet was used as the measurement trial object. The size of the magnet was smaller than measurement dimension of the system therefore the measurement dimension of the magnetic plane was made with the size of (100x 100) $\mathrm{mm}$. The initial position coordinate of the teslameter 1 and teslameter 2, respectively, set at $(430,720)$ and $(430,240)$. The trial was excuted 2 times (2 different magnet position). Each trial consist of 3 times measurement, so there's 6 data file obtained. On those data file, there's an average of 1.117 data on each file. The motor speed was set on $25 \mathrm{~mm} / \mathrm{s}$. The data reading speed was set on 10 data/s, which would caused a 2,5 mm interval on one single data.

Keywords—magnetic field measurement system, LabVIEW, controller, teslameter, stepper motor, on-off control methode, serial communication. 


\section{PENDAHULUAN}

$P^{i}$ sat Teknologi Akselerator dan Proses Bahan (PTAPB) BATAN Yogyakarta sedang meneliti dan mengembangkan sistem pengukuran medan magnet untuk alat siklotron. Siklotron merupakan sebuah akselerator untuk mempercepat gerak dari sebuah partikel bermuatan. Dalam piranti siklotron, percepatan gerak partikel dipengaruhi oleh medan listrik dan induksi medan magnet yang timbul dari kumparan. Produk yang diperoleh dari penggunaan siklotron adalah partikel bermuatan dengan tingkat energi cukup besar hingga mencapai 100 $\mathrm{MeV}$ [1].Pemanfaatan dari energi yang dihasilkan dapat digunakan dalam berbagai bidang misalnya terapi radiasi, rekayasa bahan, sterilisasi dan masih banyak aplikasi lainnya [2].

Selama siklotron beroperasi akan terjadi kenaikan temperatur pada penampang penghantar arus kumparan. Kenaikan temperatur pada penghantar arus kumparan diakibatkan oleh kebocoran arus listrik yang kemudian menimbulkan panas.Kenaikan temperatur penghantar listrik berbanding lurus dengan kenaikan tahanan listrik. Jika temperatur penghantar arus kumparan naik, maka tahanan listrik pada penghantar juga akan naik. Kenaikan nilai tahanan listrik pada penghantar akan menyebabkan nilai arus kumparan menurun pada kondisi tegangan listrik yang tetap. Perubahan nilai arus kumparan mengakibatkan besaran induksi magnetik menjadi tidak stabil. Kestabilan medan magnet dalam siklotron harus dijaga untuk menghasilkan percepatan gerak partikel yang optimal [3].

Pengukuran medan magnet pada siklotron diperlukan untuk mengetahui besar dan arah dari medan magnet yang digunakan dalam mesin siklotron.Pengukuran ini menggunakan sistem pemetaan medan magnet untuk mengetahui distribusi medan magnet pada mesin siklotron [4]. Sistem untuk mengukur medan magnet dibuat dengan tujuan untuk mempermudah, mempercepat, serta mengoptimalkan pengukuran yang dilakukan dalam dimensi pengukuran yang luas dan orde dimensi pengukuran yang kecil (contohnya, dimensi pengukuran dalam satuan $\mathrm{mm}$ ).

Terdapat dua fungsi utama dari sistem pengukuran tersebut, yaitu akuisisi data dan kendali sistem pengukuran. Fungsi akuisisi data bertugas mengambil informasi data dari obyek pengukuran. Untuk merepresentasikan fungsi ini, pada sistem pengukuran digunakan sebuah sensor magnet sebagai pendeteksi kuat medan magnet. Sedangkan fungsi kendali bertugas mengatur proses atau kerja dari sistem pengukuran. Dalam sistem pengukuran medan magnet, fungsi kendali akan diterapkan dalam sistem. Hal-hal yang akan dikendalikan dalam sistem pengukuran adalah perubahan posisi pengukuran dalam sistem koordinat kartesian. Untuk mendukung fungsi tersebut digunakan sebuah aktuator, yaitu motor stepper [5].

Pada tahun 2011, PTAPB BATAN telah melaksanakan sebuah penelitian yang dimaksudkan untuk merintis penelitian yang sedang dilakukan saat ini. Pada penelitian tersebut telah dibuat simulasi sistem pengukuran medan magnet dengan menggunakan PLC T100MD1616+ sebagai controller-nya [3]. Penelitian tersebut juga dimaksudkan sebagai uji coba implementasi dari algoritme pemrograman yang bertugas mengendalikan sistem pengukuran medan magnet. Berdasarkan penjelasan serta penelitian referensi yang sudah disebutkan, penelitian ini dilaksanakan sebagai upaya untuk membuat sebuah sistem pengukuran medan magnet.

\section{METODE PENELITIAN}

\subsection{Analisis dan Perancangan Sistem}

Penelitian yang dilakukan adalah merancang dan membangun sistem pengukuran medan magnet. Pengukuran medan magnet dilakukan dengan cara memetakan (mapping) kuat medan magnet dari setiap titik koordinat pada sumbu-x dan sumbu-y yang terdapat pada sebuah bidang magnet. Pola pemetaan akan mengikuti pola yang diterapkan dalam algoritme pemrogaman sistem. Gambar 1 merupakan blok diagram dari sistem secara keseluruhan. Sistem

IJEIS Vol. 5, No. 2, October 2015 : 133 - 144 
dibagi menjadi beberapa blok fungsi yang masing-masing mempunyai tugas yang berbeda, antara lain Controller Block, Motion Actuator Block, Data Acquisition Block, Mechanic Block, dan HMI Block.

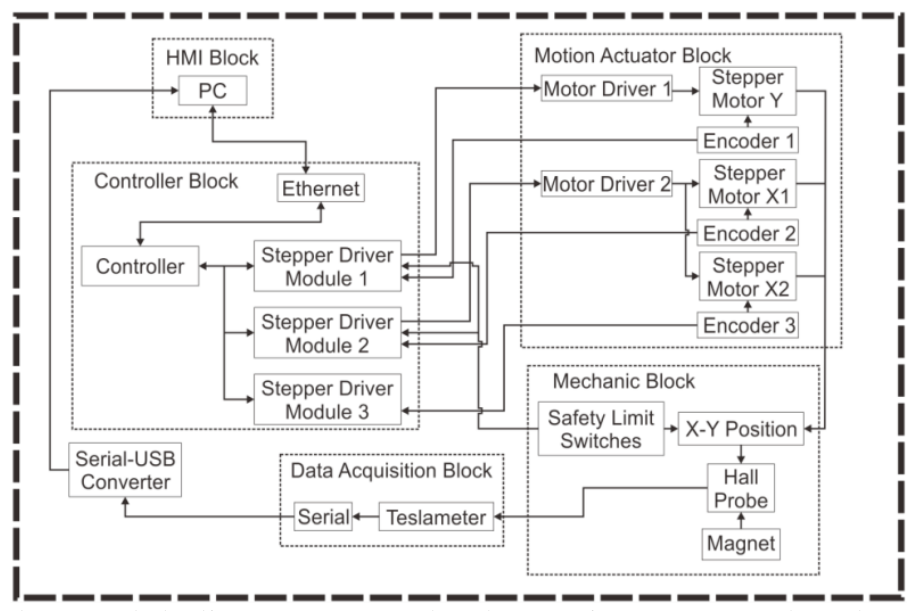

Gambar 1 Blok diagram perangkat keras sistem secara keseluruhan

Perancangan sistem mekanik yang digunakan dalam sistem terlihat dalam Gambar 2. Motor stepper adalah bagian penggerak dari sistem mekanik. Terdapat 2 motor pada sumbu-x dan 1 motor pada sumbu-y. Motor tersebut digunakan untuk memutar ball-screw yang terpasang pada masing-masing sumbu. Dua buah ball-screw yang terdapat pada sumbu-x, yang memiliki gerigi dengan jarak puncak-ke-puncak sebesar $10 \mathrm{~mm}$, dapat berputar hingga $10 \mathrm{~mm}$ tiap putaran. Sedangkan ball-screw yang terdapat pada sumbu-y, yang memiliki gerigi dengan jarak puncak-ke-puncak sebesar $5 \mathrm{~mm}$, dapat berputar hingga $5 \mathrm{~mm}$ tiap satu putaran.

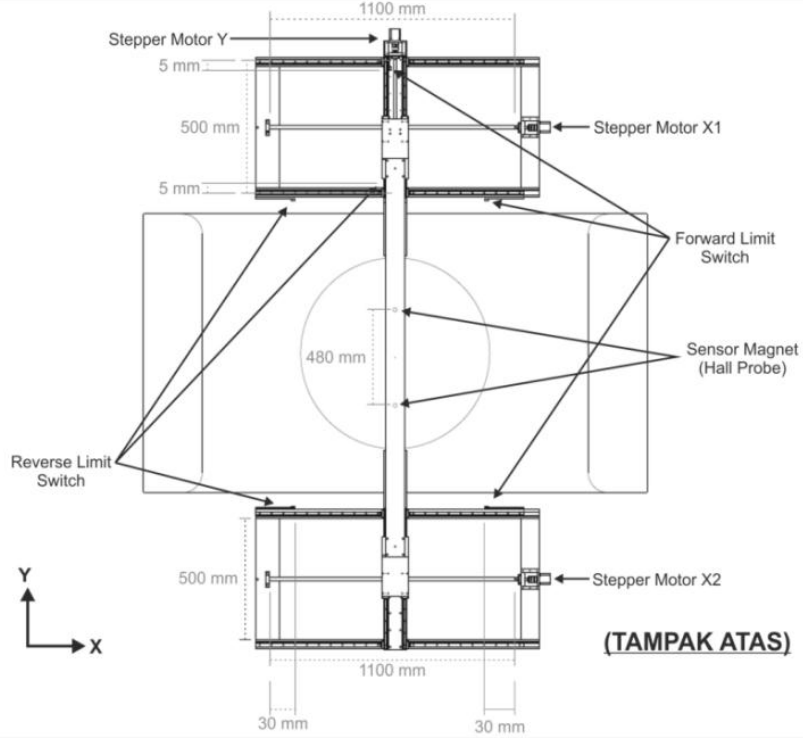

Gambar 2 Perangkaian sistem mekanik

\subsection{Implementasi Sistem}

Controller yang digunakan dalam sistem pengukuran medan magnet ini adalah controller NI cRIO-9022 ditambah dengan modul NI 9512 untuk pengatur fungsi gerakan mapping. Sensor magnet yang digunakan untuk membaca kuat medan magnet menggunakan sebuah teslameter DTM-151 Digital Teslameter dengan hall probe MPT-141. Pembuatan media antarmuka atau HMI (Human Machine Interace) dilakukan dengan menggunakan program LabVIEW. Sistem akan melaksanakan proses mapping berdasarkan flowchart yang terlihat dalam Gambar 3. 


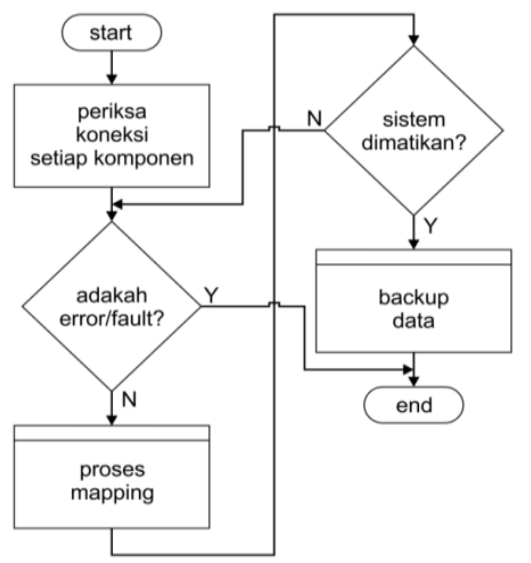

Gambar 3 Flowchart dari sistem secara keseluruhan

Berdasarkan flowchart yang ditampilkan dalam Gambar 3, fungsi utama dari sistem pengukuran medan magnet diatur dalam fungsi Proses Mapping. Flowchart dari fungsi Proses Mapping dapat dilihat dalam Gambar 4.

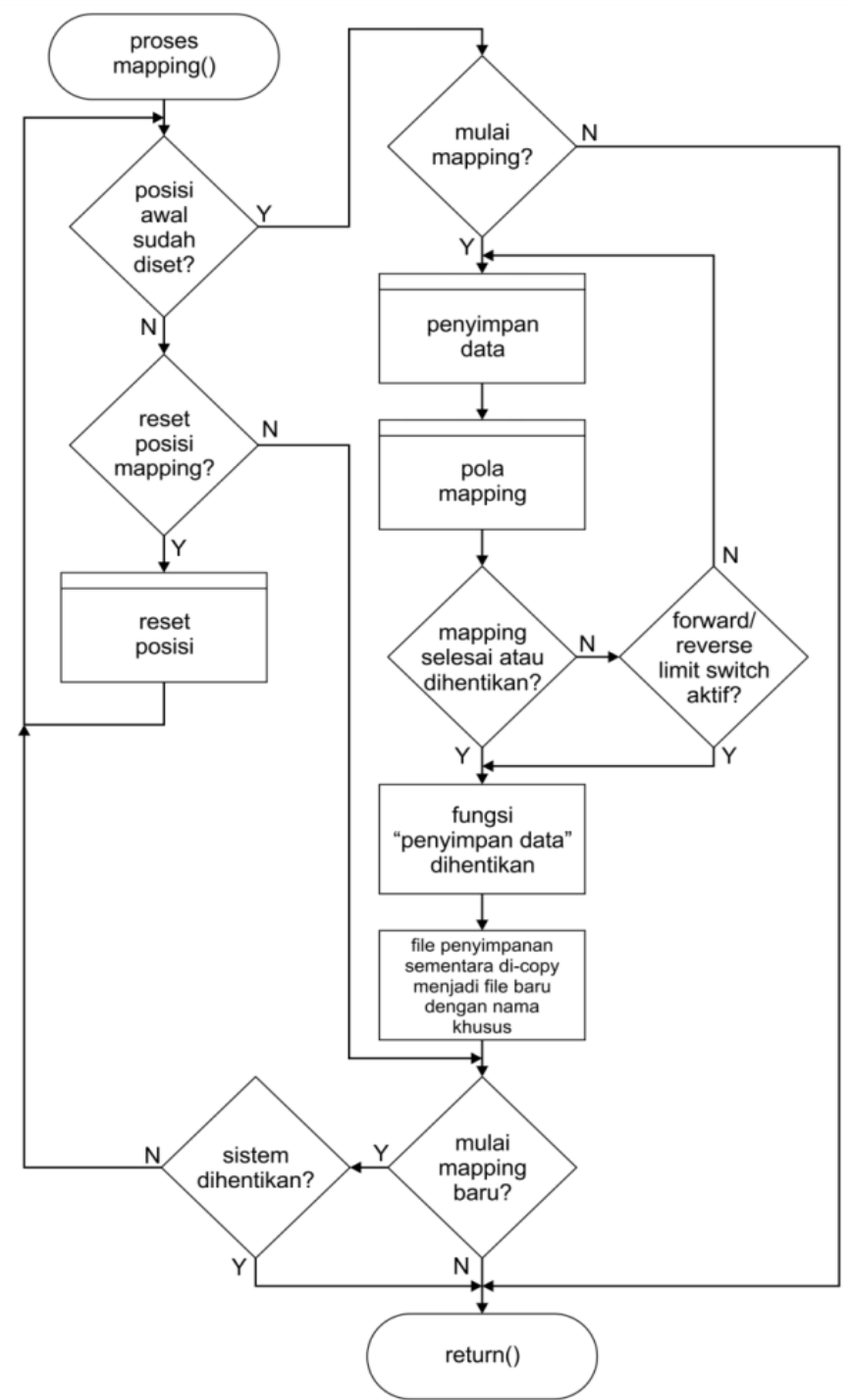

Gambar 4 Flowchart dari fungsi Proses Mapping 
Pada saat melakukan proses mapping, sistem akan memutar motor untuk menggerakkan sensor magnet mengikuti sebuah pola. Pola gerakan yang diterapkan dalam sistem ini terlihat dalam Gambar 5.

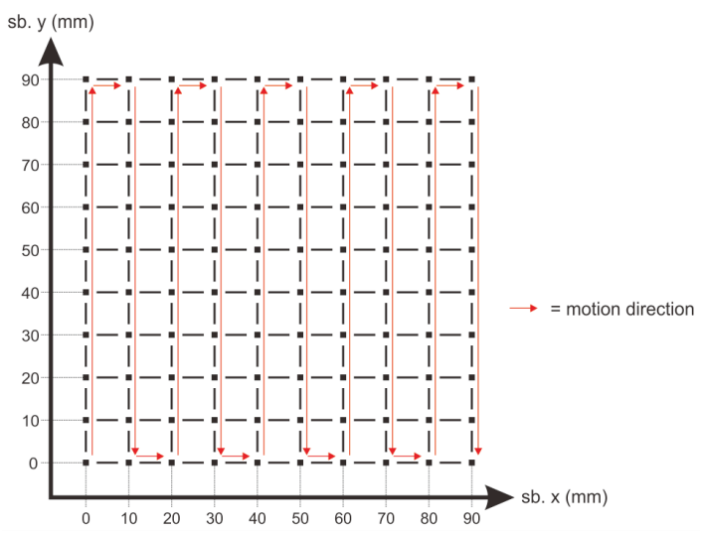

Gambar 5 Ilustrasi pola pemetaan medan magnet

\section{HASIL DAN PEMBAHASAN}

Pengujian sistem pengukuran medan magnet secara keseluruhan termasuk penggunaan magnet uji coba sebagai uji coba sebelum nantinya sistem ini digunakan untuk mengukur magnet yang akan digunakan untuk mesin siklotron. Magnet uji coba yang digunakan adalah sebuah magnet permanen, namun hingga pengujian ini dilaksanakan tidak dokumentasi mengenai spesifikasi yang pasti dari magnet tersebut. Dengan pengukuran manual menggunakan teslameter di bagian tengah magnet didapatkan nilai rata-rata maksimum kuat medan magnet adalah $\pm 0,1$ Tesla. Gambar 6 menunjukkan area yang memiliki intensitas kuat magnet lebih besar dibanding bagian lainnya dari magnet.

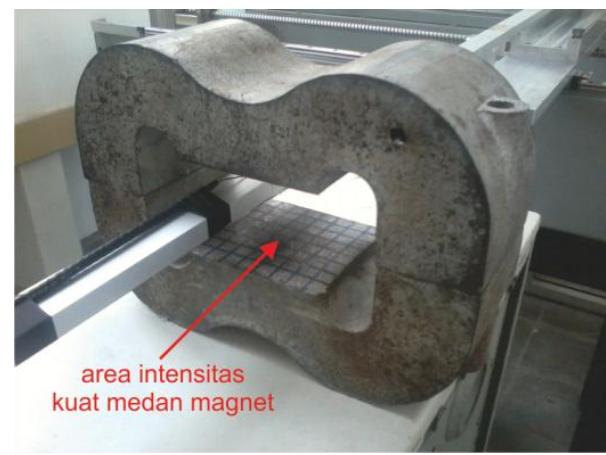

Gambar 6 Area intensitas kuat medan magnet

Pengujian ini akan dibagi menjadi 2 pengujian dengan didasarkan pada peletekan posisi magnet terhadap 2 probe yang dimiliki sistem ini. Masing-masing pengujian akan dilakukan sebanyak 3 kali proses mapping, dimana dari data yang didapatkan akan dilihat perbedaan pembacaan kuat medan magnet di antara kedua probe. Sebagaimana terlihat pada Gambar 6, area berbentuk persegi memiliki ukuran $\pm(80 \times 70) \mathrm{mm}$ dan telah diberi garis adalah area yang termasuk dalam area pengukuran. Dimensi pengukuran sendiri dibuat dengan ukuran $(100 \mathrm{x}$ 100) $\mathrm{mm}$. Kecepatan motor yang digunakan adalah $25 \mathrm{~mm} / \mathrm{s}$.

Pengujian yang pertama, magnet diposisikan pada daerah probe teslameter yang berada dekat dengan motor X1 (teslameter 1). Gambar 7 menunjukkan ilustrasi peletakan posisi magnet pada pengujian $1 \mathrm{ini}$, sedangkan denah dari posisi magnet relatif terhadap posisi $(0,0)$ dari sistem dapat dilihat pada Gambar 8. Koordinat posisi awal dari pengujian 1 ini untuk probe 
teslameter 1 adalah $(430,720)$, sedangkan koordinat posisi awal probe teslameter 2 adalah $(430,240)$.

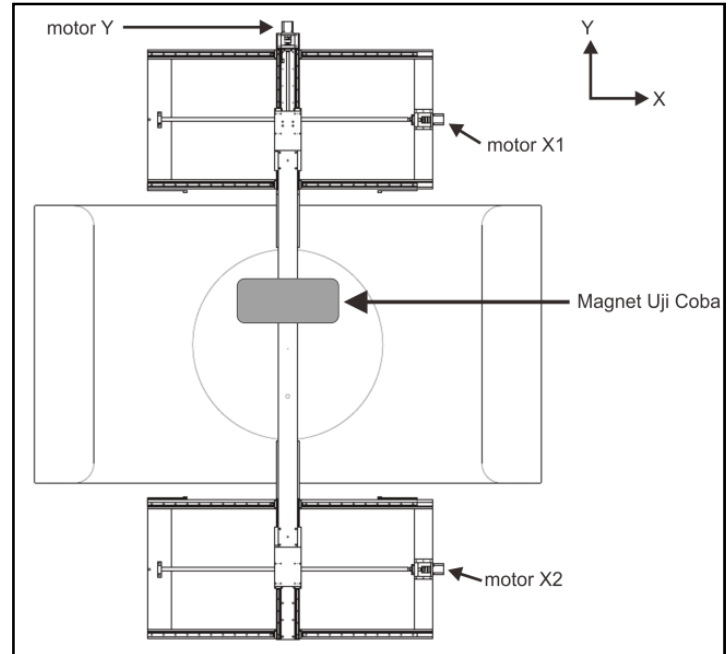

Gambar 7 Ilustrasi peletakan posisi magnet pada pengujian 1

Magnet akan diukur oleh probe teslameter 1. Probe teslameter 2 dikondisikan tanpa objek pengukuran dan digunakan sebagai pembanding data yang terbaca pada probe teslameter 1. Setelah diposisikan sesuai dengan Gambar 7 dan Gambar 8, proses mapping dijalankan hingga tercapai jumlah 3 kali proses mapping yang telah direncanakan.

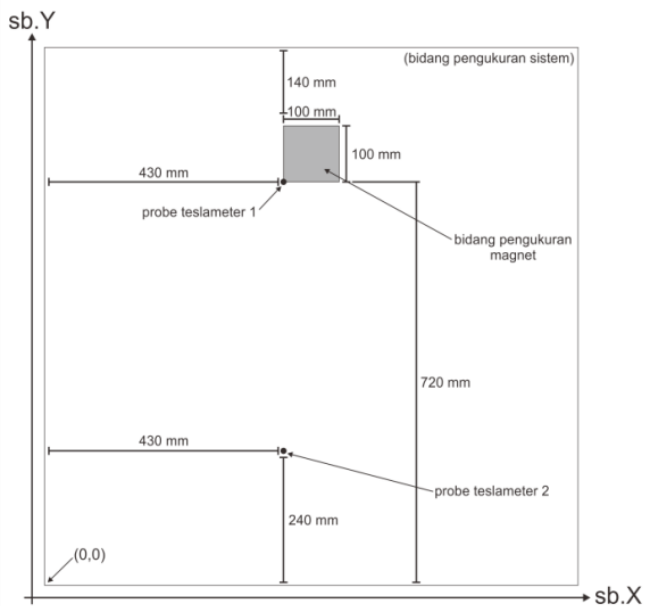

Gambar 8 Denah posisi magnet pada pengujian 1

Dari 3 kali proses mapping tersebut kemudian didapatkan 3 buah file data (Data1.txt, Data2.txt, dan Data3.txt). Data1.txt berisi 1.117 data, Data2.txt berisi 1.113 data, dan Data3.txt berisi 1.116 data. Ketiga file data dapat dilihat secara lengkap pada bagian lampiran laporan ini. Tabel 1 menunjukkan cuplikan data dari file data Data1.txt yang didapatkan dari pengujian ini.Setelah dibandingkan dari kelima file data tersebut, disimpulkan bahwa secara keseluruhan probe teslameter 1 yang berada pada area pengukuran memiliki nilai data yang lebih besar daripada probe teslameter 2 yang tidak berada pada area pengukuran. Pada daerah yang berada di sekitar koordinat $(480,750)$ atau berada di tengah area pengukuran didapatkan kuat medan magnet yang lebih besar dibandingkan dengan daerah tepian area pengukuran. Hal ini mengindikasikan adanya konsistensi pengujian dibandingkan dengan pengukuran manual yang telah dilakukan. Pengujian ini juga menunjukkan bahwa probe teslameter 1 yang digunakan dalam area pengukuran telah dapat bekerja dan dapat melakukan pengukuran dengan baik.

IJEIS Vol. 5, No. 2, October 2015 : 133 - 144 
Sebagai penggambaran untuk data dari Data1.txt dibuat grafik dengan menggunakan MATLAB dengan menggunakan perintah "plot", seperti yang terlihat pada Gambar 9.

Tabel 1 Data Pengujian 1 (Data1.txt)

\begin{tabular}{|c|c|c|c|c|c|c|c|c|c|}
\hline \multirow{2}{*}{ No } & \multirow{2}{*}{ Waktu Pengambilan Data } & \multicolumn{5}{|c|}{ Data Posisi [X,Y] (mm) } & \multicolumn{2}{|c|}{$\begin{array}{c}\text { Data Kuat Medan Magnet } \\
\text { (Tesla) }\end{array}$} \\
\cline { 4 - 10 } & & & $\begin{array}{c}\text { Posisi } \\
\text { X1 }\end{array}$ & $\begin{array}{c}\text { Posisi } \\
\text { Y1 }\end{array}$ & $\begin{array}{c}\text { Posisi } \\
\text { X2 }\end{array}$ & $\begin{array}{c}\text { Posisi } \\
\text { Y2 }\end{array}$ & $\begin{array}{c}\text { Teslameter } \\
\text { 1 (Kiri) }\end{array}$ & $\begin{array}{c}\text { Teslameter 2 } \\
\text { (Kanan) }\end{array}$ \\
\hline 1 & $31 / 07 / 2013$ & $13: 52: 37$ & 430.00 & 720.00 & 430.00 & 240.00 & 0.0289561 & 0.0020274 \\
\hline 2 & $31 / 07 / 2013$ & $13: 52: 37$ & 430.00 & 720.00 & 430.00 & 240.00 & 0.0289561 & 0.0020274 \\
\hline$\vdots$ & $\vdots$ & $\vdots$ & $\vdots$ & $\vdots$ & $\vdots$ & $\vdots$ & $\vdots$ & $\vdots$ \\
\hline 564 & $31 / 07 / 2013$ & $13: 53: 33$ & 480.00 & 760.15 & 480.00 & 280.15 & 0.1004645 & 0.0013781 \\
\hline 565 & $31 / 07 / 2013$ & $13: 53: 33$ & 480.00 & 757.65 & 480.00 & 277.65 & 0.1009341 & 0.0004784 \\
\hline 566 & $31 / 07 / 2013$ & $13: 53: 33$ & 480.00 & 755.15 & 480.00 & 275.15 & 0.1009341 & 0.0004784 \\
\hline 567 & $31 / 07 / 2013$ & $13: 53: 33$ & 480.00 & 752.65 & 480.00 & 272.65 & 0.1015828 & 0.0008205 \\
\hline 568 & $31 / 07 / 2013$ & $13: 53: 33$ & 480.00 & 750.15 & 480.00 & 270.15 & 0.1015828 & 0.0008205 \\
\hline 569 & $31 / 07 / 2013$ & $13: 53: 33$ & 480.00 & 747.40 & 480.00 & 267.40 & 0.1015885 & 0.0008195 \\
\hline 570 & $31 / 07 / 2013$ & $13: 53: 33$ & 480.00 & 745.15 & 480.00 & 265.15 & 0.1014158 & 0.0006690 \\
\hline 571 & $31 / 07 / 2013$ & $13: 53: 34$ & 480.00 & 742.65 & 480.00 & 262.65 & 0.1014158 & 0.0006690 \\
\hline 572 & $31 / 07 / 2013$ & $13: 53: 34$ & 480.00 & 740.15 & 480.00 & 260.15 & 0.1010526 & 0.0012345 \\
\hline 573 & $31 / 07 / 2013$ & $13: 53: 34$ & 480.00 & 737.65 & 480.00 & 257.65 & 0.0997227 & 0.0012332 \\
\hline 574 & $31 / 07 / 2013$ & $13: 53: 34$ & 480.00 & 735.15 & 480.00 & 255.15 & 0.0997227 & 0.0012332 \\
\hline 575 & $31 / 07 / 2013$ & $13: 53: 34$ & 480.00 & 732.65 & 480.00 & 252.65 & 0.0977022 & 0.0014033 \\
\hline 576 & $31 / 07 / 2013$ & $13: 53: 34$ & 480.00 & 730.15 & 480.00 & 250.15 & 0.0977022 & 0.0014033 \\
\hline
\end{tabular}
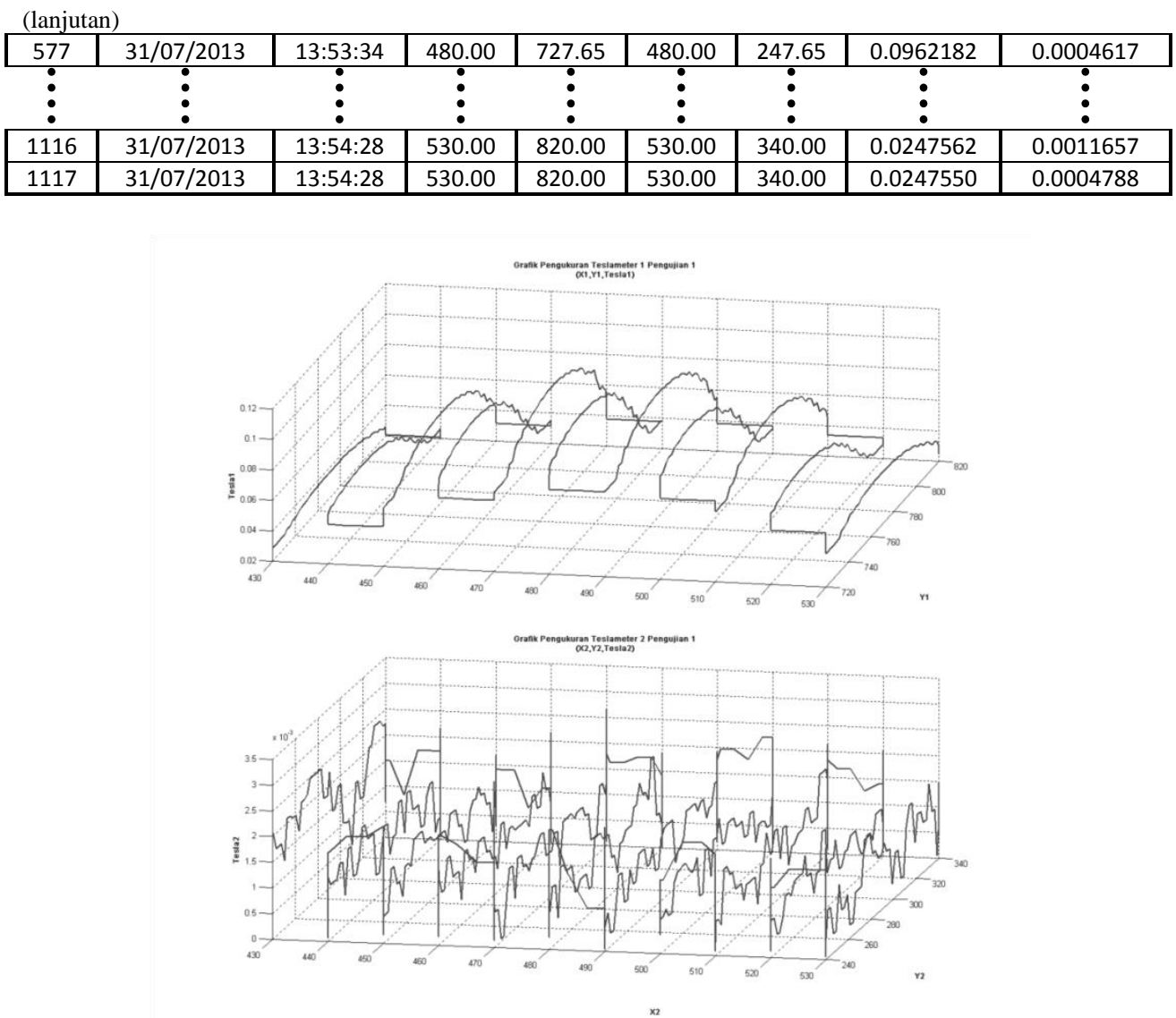

Gambar 9 Grafik data dari pengujian 1 
Pengujian yang kedua dilakukan dengan langkah yang sama seperti pengujian 1 . Magnet diposisikan sesuai dengan ilustrasi Gambar 10. Berkebalikan dengan pengujian 1, dimana probe teslameter 1 yang mengukur magnet, pengujian ini yang mengukur magnet adalah probe teslamater 2. Probe teslameter 1 dikondisikan tanpa objek pengukuran dan digunakan sebagai pembanding data yang terbaca pada probe teslameter 2 .

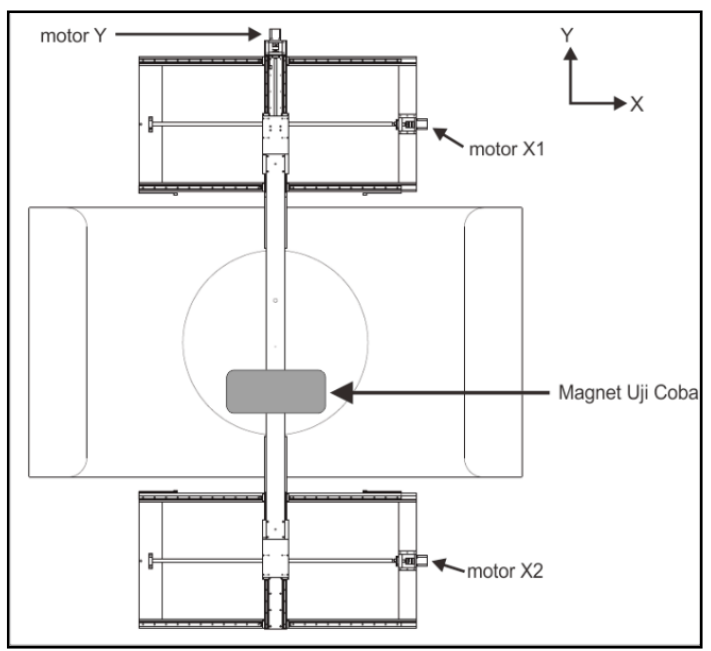

Gambar 10 Ilustrasi peletakan posisi magnet pada pengujian 2

Sama seperti pada pengujian 1, koordinat posisi awal dari pengujian 1 ini untuk probe teslameter 1 adalah $(430,720)$, sedangkan koordinat posisi awal probe teslameter 2 adalah $(430,240)$. Denah dari posisi magnet relatif terhadap posisi $(0,0)$ sistem dapat dilihat pada Gambar 11. Setelah ditempatkan pada posisi yang diinginkan, sebanyak 3 kali proses mapping dijalankan sama dengan yang telah dilakukan pada pengujian 1 .

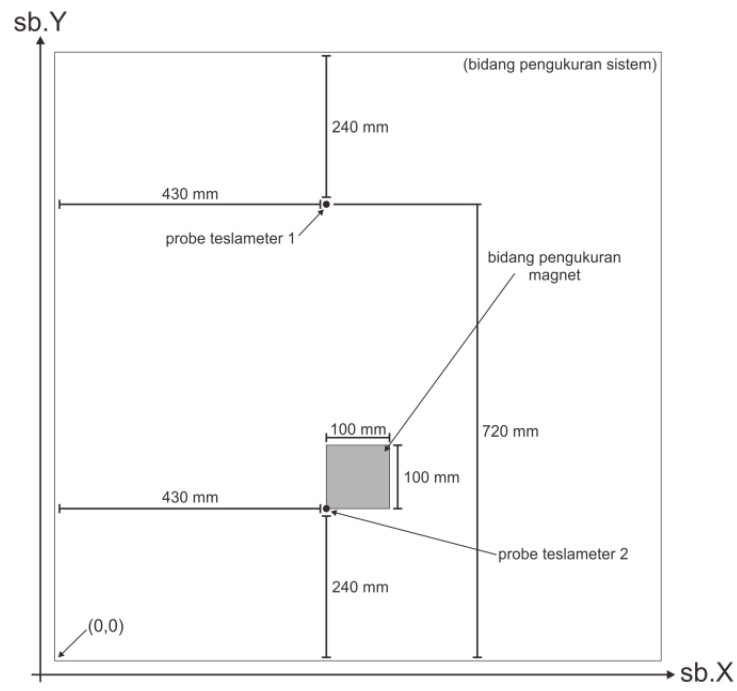

Gambar 11 Denah posisi magnet pada pengujian 2

Pengujian probe teslameter 2 juga menghasilkan 3 buah file data (Data1.txt, Data2.txt, dan Data3.txt). Data1.txt berisi 1.118 data, Data2.txt berisi 1.119 data, dan Data3.txt berisi 1.118 data. Dari data tersebut terlihat bahwa pembacaan probe teslameter 2 memiliki nilai kuat medan magnet yang lebih besar dibandingkan dengan probe teslameter 1.Tabel 2 menunjukkan cuplikan data darisalah satu file data, yakni Data1.txt, yang didapatkan dari pengujian ini. Walaupun nilai kuat medan magnet yang terbaca oleh probe teslameter 2 lebih kecil jika 
dibandingkan dengan ketika dilakukan pengujian menggunakan probe teslameter 1 , kuat medan magnet pada daerah di sekitar koordinat $(480,770)$ atau di tengah area pengukuran lebih besar dibandingkan daerah tepian area pengukuran.Untuk data dari pengujian ini juga disajikan dalam bentuk grafik yang juga dibuat dengan menggunakan MATLAB, seperti yang terlihat pada Gambar 12.

Tabel 2 Data Pengujian 2 (Data1.txt)

\begin{tabular}{|c|c|c|c|c|c|c|c|c|}
\hline \multirow{2}{*}{ No } & \multirow{2}{*}{ Waktu Pengambilan Data } & \multicolumn{3}{|c|}{ Data Posisi [X,Y] (mm) } & \multicolumn{2}{|c|}{$\begin{array}{c}\text { Dataat Medan Magnet } \\
\text { (Tesla) }\end{array}$} \\
\cline { 5 - 10 } & \multicolumn{2}{|c|}{} & $\begin{array}{c}\text { Posisi } \\
\text { X1 }\end{array}$ & $\begin{array}{c}\text { Posisi } \\
\text { Y1 }\end{array}$ & Posisi X2 & $\begin{array}{c}\text { Posisi } \\
\text { Y2 }\end{array}$ & $\begin{array}{c}\text { Teslameter 1 } \\
\text { (Kiri) }\end{array}$ & $\begin{array}{c}\text { Teslameter } \\
\text { 2 (Kanan) }\end{array}$ \\
\hline 1 & $31 / 07 / 2013$ & $13: 38: 06$ & 430.00 & 720.00 & 430.00 & 240.00 & 0.0001522 & 0.0002760 \\
\hline 2 & $31 / 07 / 2013$ & $13: 38: 06$ & 430.00 & 720.00 & 430.00 & 240.00 & 0.0001522 & 0.0002760 \\
\hline$\vdots$ & $\vdots$ & $\vdots$ & $\vdots$ & $\vdots$ & $\vdots$ & $\vdots$ & $\vdots$ & $\vdots$ \\
\hline 554 & $31 / 07 / 2013$ & $13: 39: 02$ & 480.00 & 788.15 & 480.00 & 308.15 & 0.0002989 & 0.0014788 \\
\hline 555 & $31 / 07 / 2013$ & $13: 39: 02$ & 480.00 & 785.65 & 480.00 & 305.65 & 0.0002969 & 0.0008356 \\
\hline 556 & $31 / 07 / 2013$ & $13: 39: 02$ & 480.00 & 783.15 & 480.00 & 303.15 & 0.0002930 & 0.0016528 \\
\hline 557 & $31 / 07 / 2013$ & $13: 39: 02$ & 480.00 & 780.65 & 480.00 & 300.65 & 0.0002930 & 0.0016528 \\
\hline 558 & $31 / 07 / 2013$ & $13: 39: 02$ & 480.00 & 777.65 & 480.00 & 297.65 & 0.0002895 & 0.0012208 \\
\hline 559 & $31 / 07 / 2013$ & $13: 39: 02$ & 480.00 & 775.65 & 480.00 & 295.65 & 0.0002895 & 0.0012208 \\
\hline 560 & $31 / 07 / 2013$ & $13: 39: 02$ & 480.00 & 773.15 & 480.00 & 293.15 & 0.0002864 & 0.0012200 \\
\hline 561 & $31 / 07 / 2013$ & $13: 39: 02$ & 480.00 & 770.65 & 480.00 & 290.65 & 0.0002800 & 0.0012197 \\
\hline 562 & $31 / 07 / 2013$ & $13: 39: 02$ & 480.00 & 768.15 & 480.00 & 288.15 & 0.0002800 & 0.0012197 \\
\hline 563 & $31 / 07 / 2013$ & $13: 39: 03$ & 480.00 & 765.65 & 480.00 & 285.65 & 0.0002767 & 0.0006553 \\
\hline 564 & $31 / 07 / 2013$ & $13: 39: 03$ & 480.00 & 763.15 & 480.00 & 283.15 & 0.0002733 & 0.0010847 \\
\hline 565 & $31 / 07 / 2013$ & $13: 39: 03$ & 480.00 & 760.65 & 480.00 & 280.65 & 0.0002733 & 0.0010847 \\
\hline 566 & $31 / 07 / 2013$ & $13: 39: 03$ & 480.00 & 758.15 & 480.00 & 278.15 & 0.0002698 & 0.0003818 \\
\hline 567 & $31 / 07 / 2013$ & $13: 39: 03$ & 480.00 & 755.65 & 480.00 & 275.65 & 0.0002698 & 0.0003818 \\
\hline$\vdots$ & $\vdots$ & $\vdots$ & $\vdots$ & $\vdots$ & $\vdots$ & $\vdots$ & $\vdots$ & $\vdots$ \\
\hline 1117 & $31 / 07 / 2013$ & $13: 39: 58$ & 530.00 & 820.00 & 530.00 & 340.00 & 0.0002386 & 0.0011935 \\
\hline 1118 & $31 / 07 / 2013$ & $13: 39: 58$ & 530.00 & 820.00 & 530.00 & 340.00 & 0.0002429 & 0.0008249 \\
\hline
\end{tabular}

Kuat medan magnet yang terbaca oleh probe teslameter 2 jika dibandingkan pada saat pengujian menggunakan probe teslameter 1 mempunyai nilai yang lebih kecil. Faktor lingkungan di sekitar area pengukuran dapat menjadi salah satu faktor penyebabnya. Selain itu, perbedaan kepekaan di antara kedua probe yang disebabkan waktu kalibrasi yang berbeda di antara keduanya hingga perbedaan cara penanganan terhadap kedua probe ketika persiapan pengukuran maupun ketika proses mapping dijalankan juga dapat menyebabkan perbedaan nilai yang terbaca tersebut. Namun jika merujuk kepada hasil pengambilan data secara keseluruhan, baik probe teslameter 1 maupun probe teslameter 2 telah dapat melakukan pengukuran dengan baik. 


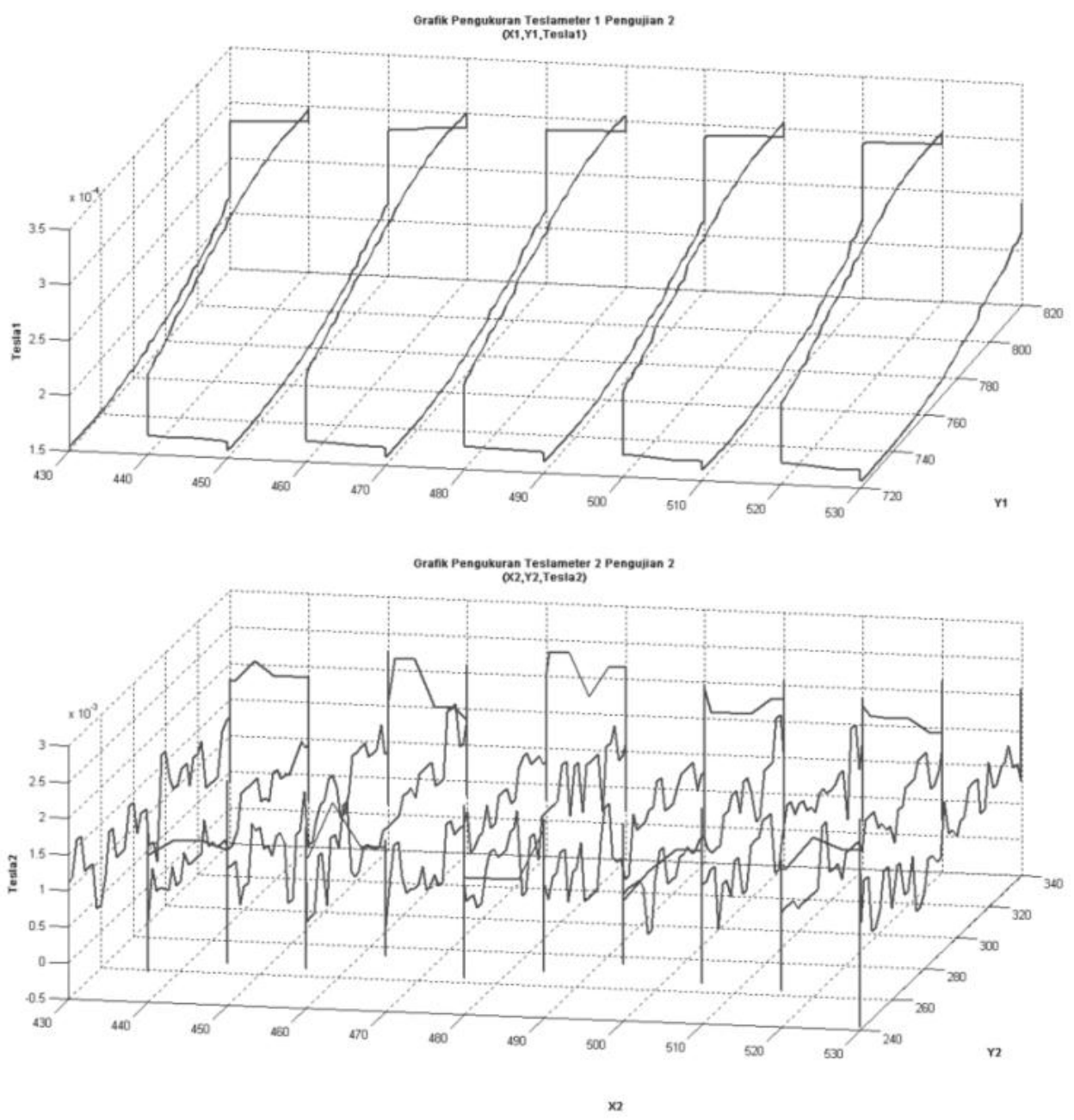

Gambar 12 Grafik data pengujian 2

Fungsi akuisisi data dalam program sistem, yang menerapkan metode fly-mode, sangat bergantung pada sistem pewaktuan.Sebagaiamana sudah disebutkan bahwa sistem ini dibuat dengan memiliki laju pembacaan data sebesar 10 data/detik. Hal yang paling berpengaruh dengan pengaturan tersebut adalah ukuran file data yang tersimpan. Proses mapping sendiri memiliki delay untuk setiap perpindahan gerakan motor antar sumbu sebesar $100 \mathrm{~ms}$ (millisecond), sehingga untuk 4 gerakan pola mapping akan didapatkan delay total sebesar 400 ms. Berdasarkan hal tersebut, jika dilakukan proses mapping dengan dimensi pengukuran yang besar, file data yang dihasilkan akan berukuran cukup besar dan berisi ribuan data.Dari 6 file data hasil pengukuran, didapatkan rata-rata jumlah data sebesar 1.117 data. Hal ini memberikan gambaran bahwa ketika pada nantinya dilaksanakan pengukuran dengan dimensi pengukuran yang lebih besar akan menghasilkan jumlah data yang lebih besar. Pemilihan kecepatan putar motor juga ikut mempengaruhi jumlah data serta interval data posisi pada tiap-tiap data. Kecepatan putar dapat digunakan sebagai indikator waktu yang dibutuhkan untuk pengukuran, karena berpengaruh terhadap cepat atau lambatnya pengukuran yang dilakukan. Dalam pengujian diberikan nilai kecepatan sebesar $25 \mathrm{~mm} / \mathrm{s}$. Ketika motor berputar, sistem akan menyimpan data posisi dengan setiap data memiliki interval $2,5 \mathrm{~mm}(25 \mathrm{~mm} / \mathrm{s} \div 10$ data/s $=2,5$ $\mathrm{mm} /$ data). Kalkulasi interval tersebut dapat berubah sesuai dengan kecepatan putar motor yang diterapkan pada saat pengukuran dilakukan. Gambar 13 menunjukkan tampilan dari HMI yang digunakan dalam sistem pengukuran medan magnet. 


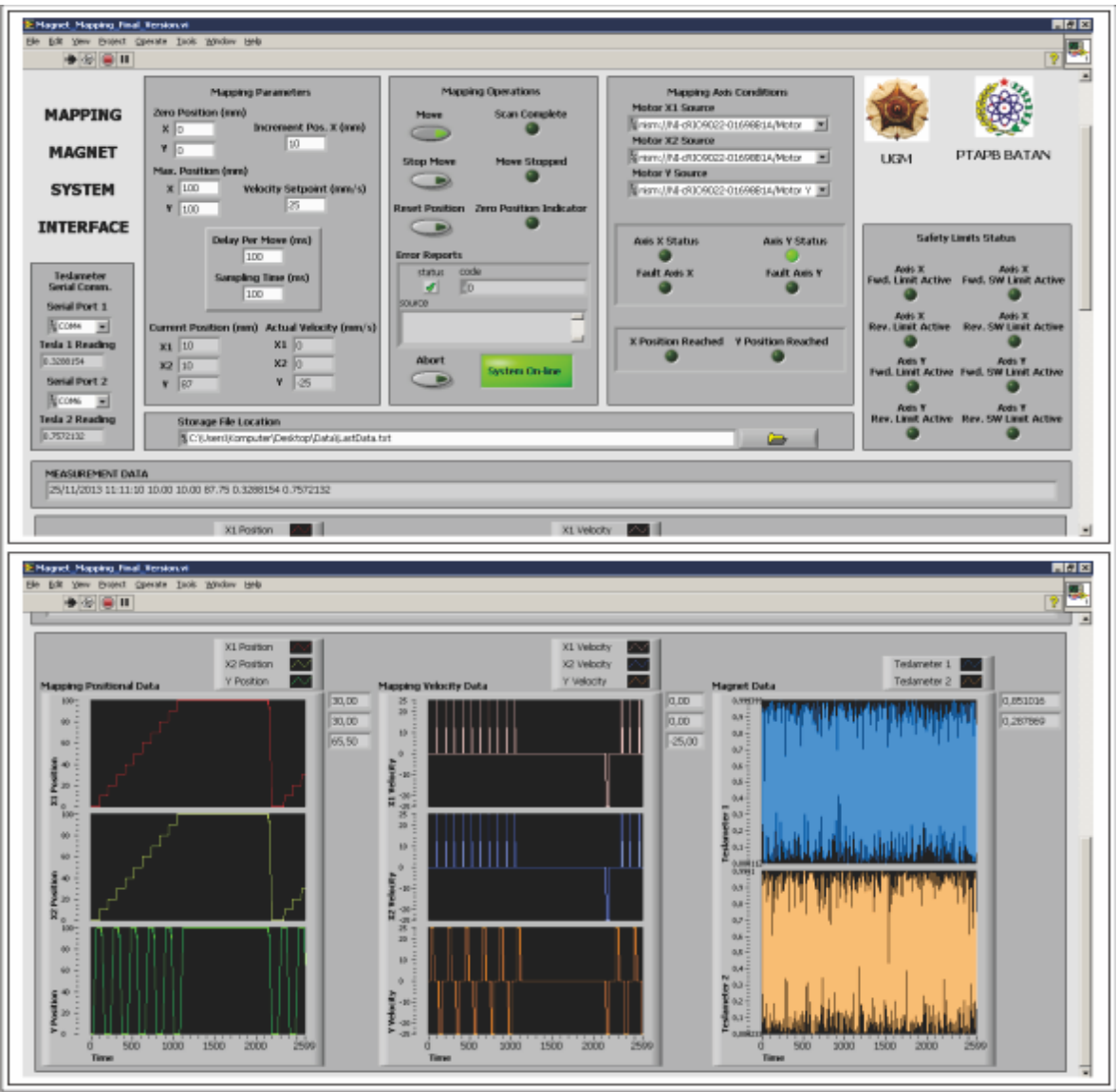

Gambar 13 Tampilan HMI Sistem Pengukuran Medan Magnet

\section{KESIMPULAN}

Berdasarkan penelitian yang telah dilaksanakan, kesimpulan yang dapat diambil adalah sebagai berikut :

1. Oleh karena bentuk dan ukuran dari magnet uji, pengujian terhadap magnet uji dilakukan dengan menggeser posisi awal terlebih dahulu menuju posisi awalpengukuran yang berada di dekat magnet. Baik pada pengujian 1maupun pengujian 2, posisi awal probe teslameter 1 diposisikan pada koordinat $(430,720)$ dan posisi awal probe teslameter 2 diposisikan pada koordinat (430,240). Pengujian 1 magnet uji diukur menggunakan probe teslameter 1 dan pengujian 2 menggunakan probe teslameter 2.

2. Berdasarkan hasil pengujian, sistem pengukuran medan magnet telah dapat melakukan pengukuran pada sebuah magnet uji dengan dimensi pengukuran sebesar $(100 \times 100) \mathrm{mm}$ dan didapatkan rata-rata 1.117 data dalam 6 file data yang berhasil didapatkan dari 2 kali pengujian (probe teslameter 1 dan probe teslameter 2 ).

3. Dari data hasil pengukuran, dengan menggunakan kecepatan $25 \mathrm{~mm} / \mathrm{s}$ dan laju pembacaan data $10 \mathrm{data} / \mathrm{s}$, didapatkan interval perubahan posisi $(\mathrm{x}, \mathrm{y})$ untuk setiap data ketika motor berputar sebesar $2,5 \mathrm{~mm}$.

4. Parameter yang dikendalikan dalam metode kendali on-off yang diterapkan dalam kendali motoradalah kecepatan putar motor. Untuk menjaga agar gerakan motor sesuai dengan pola gerakan mapping, setpoint jarak tempuh putaran motor pada masing-masing sumbu digunakan untuk membatasi gerak putar motor.

5. Data yang tersimpan berisi tanggal dan waktu pengambilan data, data posisi $(\mathrm{x}, \mathrm{y})$, serta data magnet. Data posisi untuk teslameter 1 adalah Posisi X1 dan Posisi Y1, sedangkan untuk teslameter 2 adalah Posisi X2 dan Posisi Y2. 


\section{SARAN}

1. Sistem pengukuran medan magnet yang telah dibuat masih memiliki banyak kekurangan dan membutuhkan pengembangan lebih lanjut sehingga nantinya dapat digunakan untuk mengukur medan magnet yang akan digunakan dalam mesin siklotron, terutama pada maintenance sistem mekanik agar sistem mampu melakukan pergerakan mapping secara presisi.

2. Program yang diaplikasikan dalam sistem pengukuran medan magnet masih dapat dikembangkan lagi agar dapat menjadi program yang dapat bekerja secara efektif dan efisien.

3. Penyesuaian sistem pengukuran medan magnet terhadap keadaan lingkungan sekitar (ambience) sangat perlu untuk diperhatikan agar tidak mempengaruhi kinerja dari sistem.

\section{DAFTAR PUSTAKA}

[1] Prior, C.R., 2004, "The Physics of Accelerators", Rutherford Appleton Laboratory and Trinity College, Oxford.

[2] Bryant, P.J., 2008, “History And Applications Of Accelerators”, CAS Frascati.

[3] Aditya, A., 2011. "Simulasi Sistem Akuisisi dan Kendali Pengukuran Medan Magnet Menggunakan PLC T100MD1616+", Skripsi, Jurusan Ilmu Komputer dan Elektronika FMIPA UGM, Yogyakarta.

[4] Yang, J., Liu, K., Qin, B., Li, D., Hu, T., Cao, L., Xiong, J., Xiong, Y., Yu, T., 2009, "Magnetic Field Measurement System for Cychu-10", Huangzhou University of Science and Technology, China.

[5] Park, K.H., Jung, Y.G., Kim, D.E., Kang, B.K., Yoon, M., Chai, J.S., Kim, Y.S., 2005, "Field mapping system for cyclotron magnet", Pohang University of Science and Technology, Pohang. 